\title{
Effects of Vortex Generators on the Thermal Flow Characteristics of Ferrofluids
}

\author{
Jae-Hee Kim ${ }^{1}$, Youn-Jea Kim² \\ ${ }^{1}$ Graduate School of Mechanical Engineering, Sungkyunkwan University \\ Suwon 16419, Republic of Korea \\ Jaehee29@skku.edu \\ ${ }^{2}$ School of Mechanical Engineering, Sungkyunkwan University \\ Suwon 16419, Republic of Korea \\ yjkim@skku.edu
}

\section{Extended Abstract}

Plate fin heat exchangers (PFHEs) are encountered extensively in many industrial processes such as heating, cooling, vehicle radiators and other fields [1]. Vortex generators installed in PFHE are capable of vortex formation and flow control, which is a promising technology to meet such requirements as low cost and high performance [2]. Various types of plates, such as flat, wavy, and pin, are applied to the flow channel with vortex generators. This technique interferes with swirling fluid flow, allowing a large exchange between fluid particles of the entire channel volume [3]. The working fluid used in other researches has been mainly using newtonian fluid such as nano fluid and water [4]. However, ferrofluids, which are effect in heat dissipation such as electronic devices and attracting attention as new heat dissipation materials, are non-newtonian fluids and colloidal solutions containing 10nm sized magnetic particles [5]. When an electromagnetic field is applied to such a magnetic fluid, it is characterized by its high thermal conductivity [6]. In particular, when the vortex generator is installed in the channel, the vortex flow promotes the heat transfer, and the position and shape of vortex generator are important parameters for increasing the vorticities [7]. In this study, 2-D microchannel was formed to identify more accurately the flow of ferrofluids. In addition, change of thermal flow characteristics due to vortex generators was confirmed when a magnetic field is applied to the microchannel. Behaviors of ferrofluids in microchannel were investigated using the commercial code, COMSOL Multiphysicis. Nusselt number, temperature distribution and pressure drop of ferrofluids according to various configurations of vortex generator were obtained and results were graphically depicted with various flow conditions. Results show that the heat transfer depends on the location and geometry of the vortex generators. As a result, the average Nusselt number was improved by about $30 \%$ compared with the reference model.

\section{Acknowledgment}

This work was supported by the National Research Foundation of Korea (NRF) grant funded by the Ministry of Education, Science and Technology (2017R1D1A1B03036263).

\section{References}

[1] K. Boukhadia, H. Ameur, D. Sahel and M. Bozit, "Effect of the perforation design on the fluid flow and heat transfer characteristics of a plate fin heat exchanger," International Journal of Thermal Sciences, vol. 126, pp. 172180, 2018.

[2] M. Khoshvaght-Aliabadi, F. Hormozi and A. Zamzamian, "Experimental analysis of thermal-hydraulic performance of copper-water nano fluid flow in different plate-fin channels," Experimental Thermal and Fluid Science, vol. 52, pp. 248-258, 2014.

[3] A. Sabaghan, M. Edalatpour, M. C. Moghadam, E. Roohi and H. Niazmand, "Nanofluid flow and heat transfer in a microchannel with longitudinal vortex generators: Two-phase numerical simulation," Applied Thermal Engineering, vol. 100, pp. 179-189, 2016. 
[4] M. Khoshvaght-Aliabadi, F. Hormozi and A. Zamzamian, "Role of channel shape on performance of plate-fin heat exchangers : experimental assessment," Experimental Thermal and Fluid Science, vol. 52, pp. 248-258, 2014.

[5] F. Herchl, K. Marton, L. Tomco, P. Kopcansky, M. Timko, M. Koneracka and I. Kolcunova, "Breakdown and partial discharges in magnetic liquids," International Journal of Thermal Sciences, vol. 79, pp. 183-193, 2014.

[6] H. S. Seo, J. C. Lee, I. J. Hwang and Y. J. Kim, "Flow characteristics of ferrofluid in a microchannel with patterned blocks," Materials Research Bulletin, vol. 58, pp. 10-14, 2014.

[7] A. Sinha, H. Chattopadhyay, A. K. Iyengar and G. Biswas, "Enhancement of heat transfer in a fin-tube heat exchanger using rectangular winglet type vortex generators," International Journal of Heat and Mass Transfer, vol. 101, pp. 667-681, 2016. 